\title{
STUDY AND EXAMINATION OF THE IMPLEMENTS USED FOR SECURING PELVIS BONE
}

\author{
János Simonovics ${ }^{1}$, Tamás Bodzay ${ }^{2}$, Károly Váradi $^{1}$ \\ ${ }^{1}$ Budapest University of Technology and Economics, Faculty of Mechanical Engineering \\ Department of Machine and Product Design, Budapest \\ ${ }^{2}$ National Institute of Traumatology and Emergency Medicine, Budapest \\ janos@simonovics.hu
}

\begin{abstract}
Our goal was to compare the direct plate known as the "gold standard" technology in case of a pelvis fracture with the H-plate technology reinforced with iliolumbar fusion and the pelvis screwing technology reinforced with iliolumbar fusion, especially focusing on the matter of stability.
\end{abstract}

In our work we studied and examined the securing possibilities and stability of the transforaminal pelvis fracture using the finite element analysis. My colleauges and I created the anatomically correct model (including the $4^{\text {th }}$ and $5^{\text {th }}$ lumbars and cartilages under the lumbars). To create the model we used a previous geometric model used for older preceding analyses. During the modeling we perfected the geometry; we separated the different bone regions and paid close attention to create the scale model of the implements. The placements of the implements are appropriate and in accordance with real surgery procedures. We examined three different cases: standing on the healthy leg, standing on both legs and standing on the injured leg. The boundary conditions for the finite element analysis: the femur is fixed and in case of standing on one leg the opposing side of the hip bone is fixed on both the $\mathrm{X}$ and $\mathrm{Z}$ axes directions. Furthermore both hip bones are fixed on the $\mathrm{Y}$ axis direction, and this applies when standing on both legs as well. We added the load to the $4^{\text {th }}$ lumbar on the model. The value of the load is $500 \mathrm{~N}$ and the direction is $-\mathrm{Z}$. We defined surface to surface connection between the femur and acetabulum and also between the side of the symphysis pubica and the fracture ends. We defined bonded connection between all the other components. In our analyses and evaluation we examined the arising stress values and also the displacements in the cortical and spongiosa regions and in the implements. We examined the elongation of the ligaments in the pelvis and measured the maximal distance between the fracture ends under load.

Considering the results of the stress states, the iliolumbar fusion technologies provide more stability. Therefore it is recommended to use these technologies, not mentioning the fact that the dorsal exposure puts the patient through considerably less trauma.

Considering the results of the fracture ends displacements it can be declared that the reason for the existence of the H-plate technology reinforced with iliolumbar fusion cannot be questioned. Therefore continuing the research can be justified by further analyzing and examining dynamic loads on models extracted from CT images.

Keywords: sacrum; fracture; transforaminal 


\section{Introduction}

According to the data, in 1995 there were 64,000 registered bone fractures as hospitalized patients, and this number reaches 85,000 if we count in the outpatients (patients, who are able to walk with walking cast) as well. Among the outpatients there were 1572 registered pelvis fractures.

The pelvis usually gets injured by a high impact force, and this is mostly a part of a polytrauma. These injuries heal with high functionality damage, therefore the surgery of the rotationally and vertically instable pelvis ring injures obviously is needed. The direct plate technology, known as the "gold standard" of the fractured sacrum raises the question, if it is possible to use a fixing technology, which during the trauma of the surgery is smaller, but the stability remains the same. During the comparison, the direct plate technology will be examined against the $\mathrm{H}$-plate technology reinforced with iliolumbar fusion and the pelvis screwing technology reinforced with iliolumbar fusion, and the transsacral plate technology reinforced with iliolumbar fusion. There is a limited amount of results deduced from the comparison of the biomechanical analysis due to ethical, technical and hygiene reasons. The limited number of results calls for a new method, which is the finite element method (FEA).

My colleauges and I created a new improved model from a previous geometric one, which corresponds with the transforaminal fractures. During the development of the model, we tried to simulate real conditions of a surgery. We added the $4^{\text {th }}$ and $5^{\text {th }}$ lumbars with the cartilages to the model, and also divided the different bone members. Furthermore we paid close attention to create the exact sized model of the implements used in clinical surgeries, and the punctual placements of these parts to the pelvis. We examined the above mentioned fixing technologies in case of standing on one leg and also on two legs, using the anatomically correct boundary conditions. We compared and evaluated the different technologies according to the arising stresses, displacement of the fracture ends and elastic states.

\section{Methods}

There are different ways to extract information needed to use the finite element analysis, such as the dense based model extracted from CT or the point cloud based model extracted from CT, which is a simplified model using surfaces stretched onto the point cloud. In order to speed up the calculation, the most likely model to use is the simplified one, which is anatomically correct, but there is some negligence about the model. There was an existing model at our disposal to use in the biomechanical analysis, on which we made the necessary modifications. In addition to the pelvic ring, the $4^{\text {th }}$ and $5^{\text {th }}$ lumbars were added to the model with the cartilages below. We had to modify the sacrum in order to implement the $5^{\text {th }}$ lumbar to the pelvis. We used a plastic medical pelvis and a spinal cord to measure and create the exact model of the additional parts. During the modeling we paid attention to the curve of the spinal cord and the fitting of the two lumbars. My colleauges and I used the ProEngineer Wildfire 4 M60 engineering program to create the modified model. Obviously the fracture is secured with implements that are fixed with screws to the bone; therefore part of the load will be projected to these screws. It was necessary to examine the nature and structure of the bone in the vicinity of these screws. The material properties cannot be neglected, thus these give the mechanical properties of the bone. For example, in the cortical region, which is a sponge like region, the material property numbers are consider- 
ably smaller. For this particular reason we divided the hard and spongy regions in the model. The cortical part is about $3 \mathrm{~mm}$ thick, and the spongiosa is located within. During the analysis we examined the sacrum fracture, more closely the transforaminal fracture, which causes rotational and vertical instability. Usually, when these high impact traumas occur, the ligamentum sacrospinale and ligamentum sacrotuerale, and also the symphysis pubica are torn on the side of the fracture. We took these effects in account in the model. The geometric model of the transforaminal fracture is shown on the Figure 1.

The sacrum fracture line is directly secured with a reconstructional plate, which is fixed with spongiosa screws. This surgery is carried out with ventral exposure technology. The plate is $3 \mathrm{~mm}$ thick, $10 \mathrm{~mm}$ wide, and the gap between the drill holes is $8 \mathrm{~mm}$. The symphysis tear is secured with a longer bridging reconstructional plate, which is fixed with two cortical screws to the pubic bone. The diameter of the cortical bone is $3.5 \mathrm{~mm}$, core diameter is $2.4 \mathrm{~mm}$, head diameter is $6 \mathrm{~mm}$, and the length is $10-110 \mathrm{~mm}$. The direct plate technology is carried out with a high trauma surgery, which takes a longer recovery process, but the remaining fracture parts have smaller amplitude of

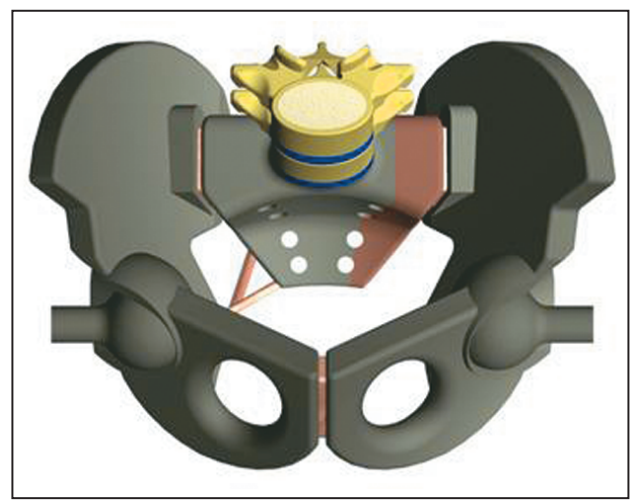

Figure 1. Geometric model of the transforaminal fracture movements. The x-ray picture of the direct plate technology can be seen on the Figure 3, and the geometric model on the Figure 2.

The H-plate technology requires dorsal surgery, which is performed by the incision over the butt cheeks. The sacrum is reached by putting aside the muscles. The fracture is secured with H-plates, which are fixed with cortical screws. The symphysis tear is similar to the direct plate technology and is secured with reconstructional plates, which are fixed with two-two cortical screws to the two sides of the pubic bone. The $\mathrm{H}$ plate is $25 \mathrm{~mm}$ long, $1 \mathrm{~mm}$ thick, and the hole diameter is $3.5 \mathrm{~mm}$. The hole distance in between is $18 \mathrm{~mm}$. The parameters of the cortical screws for fixing the $\mathrm{H}$-plate are exactly the same to the direct plate technology. During the examination of the H-plate technology we used iliolumbar fusion reinforcement. At this reinforcement method, dorsal exposure is used, that way giving access to the lumbars and the hip bone. Two-two screws are placed through the pedunculus of the lumbar extension to the lumbar body itself. Through these, one-one connecting lengthwise rods are extended until the screws fixed in the hip bone. With the help of these rods part of the load is transferred to the hip bone. This securing method puts a smaller load on the

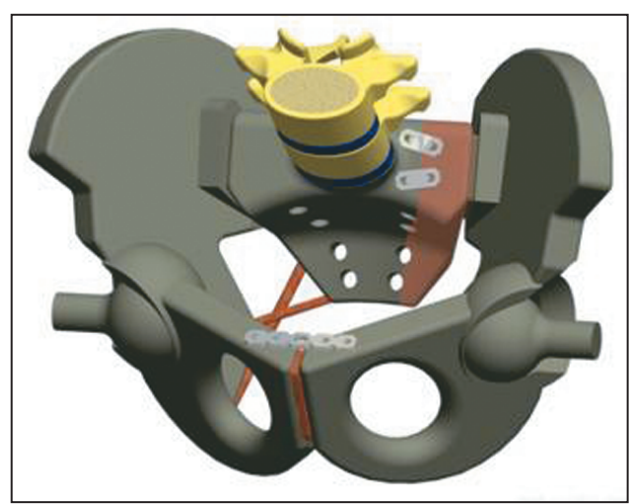

Figure 2. Geometric model of the direct plate securing technology 
sacrum, which results in a smaller displacement, thus the fixation is more secure. The lengthwise connecting rods under the lumbar are reinforced by a transversal stabilizing rod. The purpose is to reduce the movements of the bridging parts, and to compensate the stresses. The x-ray picture of the H-plate technology can be seen on the Figure 3, and the reinforced with iliolumbar fusion is on the Figure 4.

The H-plate iliolumbar fusion technology was constructed in light of the above mentioned facts and can be seen on the Figure 5 .

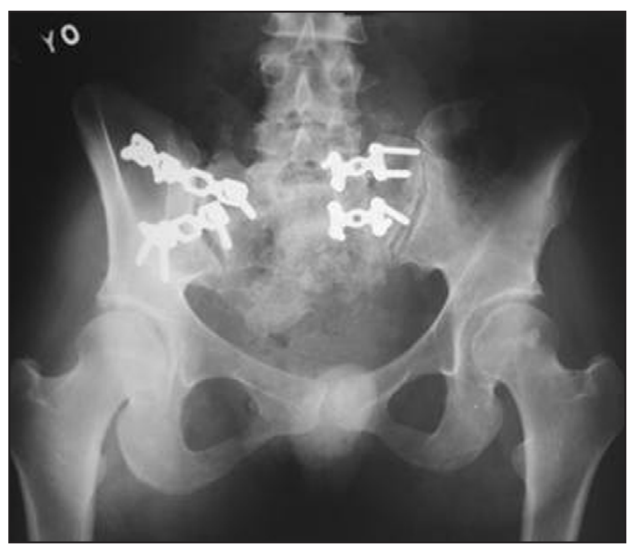

Figure 3. X-ray picture of the $\mathrm{H}$-plate and direct plate technology

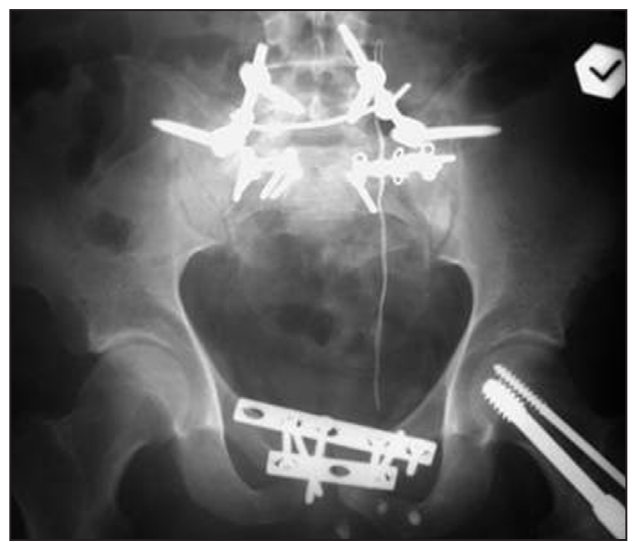

Figure 4. X-ray picture of the iliolumbar fusion technology

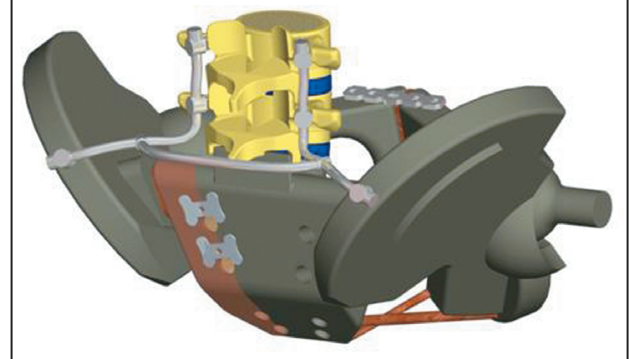

Figure 5. Geometric model of the H-plate technology reinforced with iliolumbar fusion

The pelvis screwing technology does not bear the necessity of exposure. The screws are placed with the help of an x-ray amplifying machine, which gives a real time picture of the surgery. After the anatomical reposition, the iliosacralis screws are inserted from lateral position. The drilling and placement of the screws are monitored from inlet and outlet views as well. The selection of the appropriate screws is important. These screws need to go further than the fracture line, so the length is a factor. The long thread is vital in the stability, without this the screws are not reliable. The thread length is usually 16, 32, 48 and $64 \mathrm{~mm}$ and the screw length is about $65-125 \mathrm{~mm}$. The pelvis screwing technology is shown on the Figure 6. Similarly to the H-plate technology, we used iliolumbar fusion reinforcement for the examination.

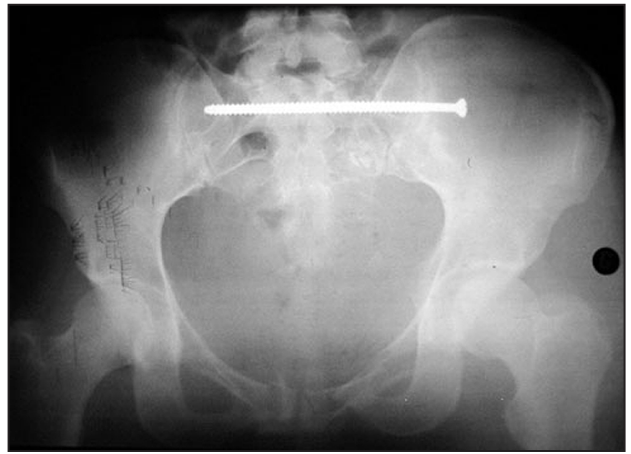

Figure 6. X-ray picture of the pelvis screwing technology 
As it was mentioned before, we considered the different material properties of the cortical and spongiosa regions before using the finite element analysis. My colleauges and I separated these regions in the sacrum, lumbars, hip bone and pubic bone. For those regions that were not separated we defined homogeneous material properties. Using $90 \%$ spongiosa and $10 \%$ cortical region in the homogeneous parts

the elasticity modulus:

$0.9 \cdot 400 \mathrm{MPa}+0,1 \cdot 17,000 \mathrm{MPa}=2,060 \mathrm{MPa}$,

the Poisson factor:

$0.9 \cdot 0.2+0.1 \cdot 0.3=0.21$.

The material properties of the bones, ligaments, joints, cartilages, implements and screws are shown in the table below. Each component is considered to be isotropic and linearly elastic.
We used brick and tetrahedral elements for meshing the model in the finite element analysis. During the meshing we also considered and separated the cortical and spongiosa regions. The examination consists of the three main conditions; standing on two legs, standing on the healthy leg, and standing on the injured leg. As defining the boundary conditions, the hip bone is fixed on the $\mathrm{Y}$-axis direction, corresponding to the muscles responsible to keep the pelvis in a standing fixed position. In case of standing on one leg the musculus gluteus medius (part of the hip muscles) prevents the pelvis to topple to the moving side, keeping the hip bone in a straight position. In light of this, I fixed the $\mathrm{X}$ and $\mathrm{Z}$ axis directions on both standing on the healthy and injured leg cases as well. The boundary conditions defined for the femur in case of standing on both legs are fixed, while standing on one leg logically the appropriate side femur is fixed. In

\begin{tabular}{|l|l|c|c|}
\hline \multicolumn{2}{|c|}{ Material properties } & Elasticity modulus [MPa] & Poisson factor \\
\hline \multirow{4}{*}{$\begin{array}{l}\text { Screws and plates used } \\
\text { for implements }\end{array}$} & H-plate & 200,000 & 0.28 \\
\cline { 2 - 4 } & Direct plate & 200,000 & 0.28 \\
\cline { 2 - 4 } & Reconstructional plate & 200,000 & 0.28 \\
\cline { 2 - 4 } & Screws & 200,000 & 0.28 \\
\cline { 2 - 4 } & Elements of the iliolumbar fusion & 200,000 & 0.28 \\
\hline
\end{tabular}

\begin{tabular}{|l|l|c|c|}
\hline \multirow{3}{*}{ Bones } & Corticalis region & 17,000 & 0.3 \\
\cline { 2 - 4 } & Spongiosa region & 400 & 0.2 \\
\cline { 2 - 4 } & Homogeneous region & 2,060 & 0.21 \\
\hline
\end{tabular}

\begin{tabular}{|l|l|l|l|}
\hline Cartilages & Cartilages under the lumbars & 50 & 0.2 \\
\hline
\end{tabular}

\begin{tabular}{|l|l|c|c|}
\hline \multirow{2}{*}{ Joints } & Symphysis & 50 & 0.2 \\
\cline { 2 - 4 } & Pelvis joint & 68 & 0.2 \\
\hline
\end{tabular}

\begin{tabular}{|l|l|l|l|}
\hline \multirow{2}{*}{ Ligaments } & Ligamentum sacrotuberale & 355 & 0.2 \\
\cline { 2 - 4 } & Ligamentum sacrospinale & 355 & 0.2 \\
\hline
\end{tabular}

Table 1. Material properties 
every case the $4^{\text {th }}$ lumbar transfers the load. This load is about $500 \mathrm{~N}$ for an average adult calculated from the weight of the upper body part. The direction of the load is $(-\mathrm{Z})$. In the geometric model between the femur and the acetabulum, and between fracture surfaces on the sacrum (both cortical and spongiosa regions), and between the side of the symphysis and corresponding pubic bone, surface to surface connection was defined. Every other part is connected to each other with the bonded function. The examination determines the amount of the arising stresses and displacement. With the defined boundary conditions the gap between the fractured sides are measurable. Based on these results the stability

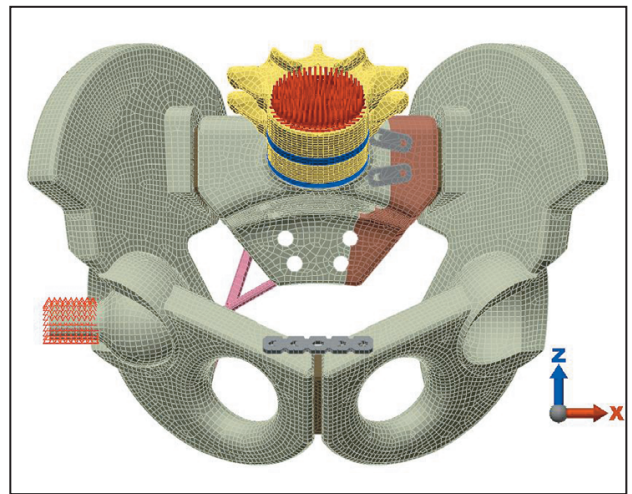

Figure 7. Boundary conditions and meshing of the direct plate technology

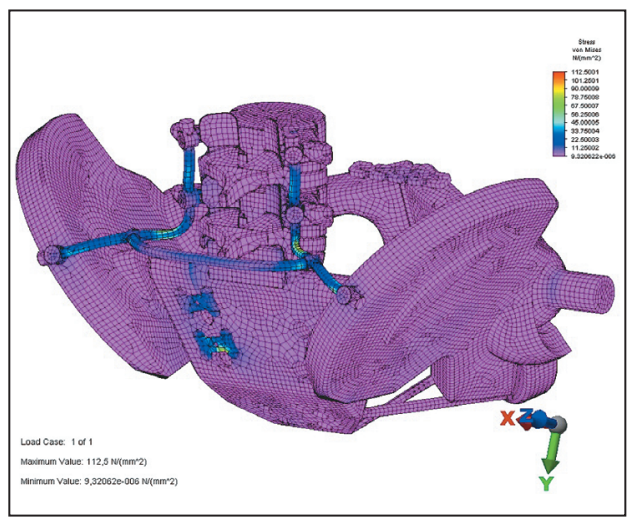

Figure 8. Stress states of the H-plate technology reinforced with iliolumbar fusion of each technology can be determined and evaluated. We used the Algor v19 SP1 program for the finite element analysis. The direct plate technology while standing on the healthy leg is shown on the Figure 7.

\section{Results}

The Figure 8 and 9 shows the result of stress and displacement while standing on both legs using the $\mathrm{H}$-plate technology reinforced with iliolumbar fusion. The Figure 10 and 11 show the results of stress and displacement while standing on the healthy leg using the Pelvis screwing technology reinforced with iliolumbar fusion.
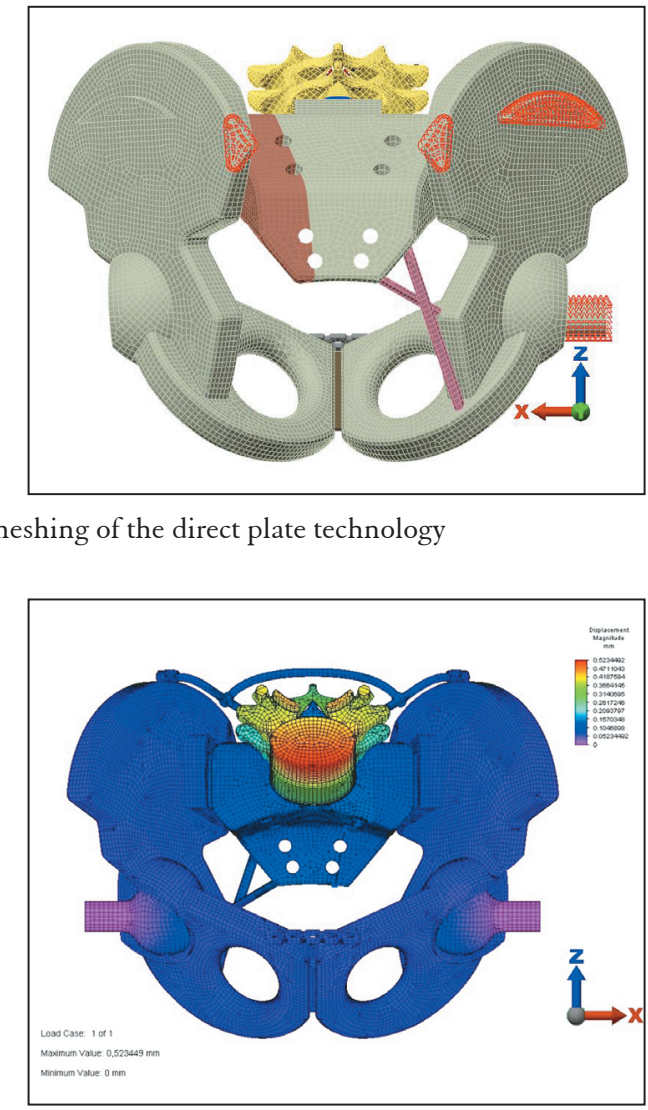

Figure 9. Displacement of the H-plate technology reinforced with iliolumbar fusion 


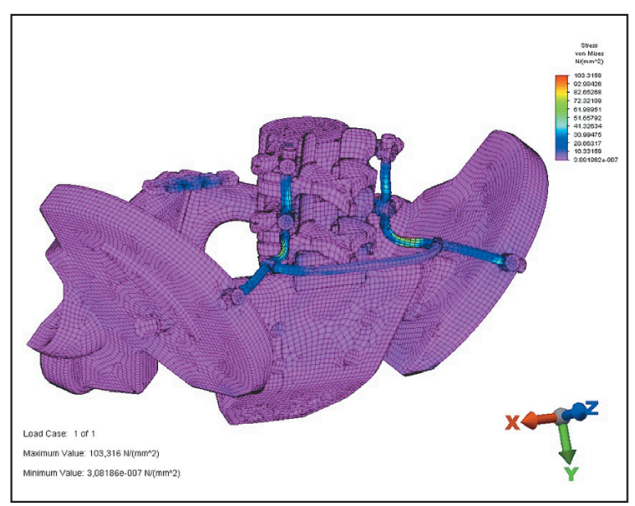

Figure 10. Stress states of the Pelvis screwing technology reinforced with iliolumbar fusion

For the sake of simplicity and better understanding, we summarized the results in the table shown below.

In the cortical bone region, the highest amount of stress arises in case of a transforaminal fracture secured with direct plate technology. It is notable that during the iliolumbar fusion the maximal arising stress isn't located in the near vicinity of the fracture on the sacrum, but rather in the lumbars, where the fixing screws for the lengthwise rods are placed. The most preferable securing method in the cortical bone region considering the arising stresses is the H-plate technology. The highest stress values are shown in the Table 2.

In the spongiosa bone regions the direct plate technology somehow is not as good as the

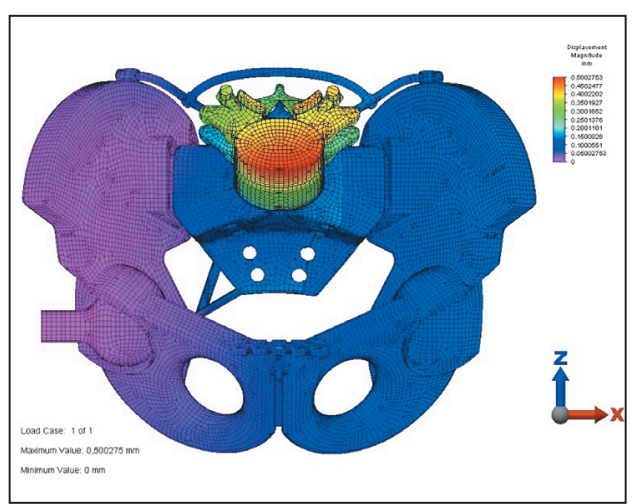

Figure 11. Displacement of the Pelvis screwing technology reinforced with iliolumbar fusion

other ones. Considering the results the best securing method for the spongiosa bone region is the H-plate technology with iliolumbar fusion as well. The highest stress values can be seen in the Table 3. The arising stresses in the implement parts are below of the allowable $800 \mathrm{MPa}$ by a considerable amount. This means that the arising stresses in the implements are not affecting any of the three technologies. Therefore each method is usable and appropriate.

During the analysis of the elongation of the ligaments, my colleauges and I examined the elongation of both the ligamentum sacrospinal and the ligamentum sacrotuberal. It is noticeable from the results that the ligamentum sacrospinal has the higher value of elongation.

\begin{tabular}{|c|c|c|c|}
\hline \multirow{2}{*}{$\begin{array}{l}\text { Arising maximal stress } \\
\text { in the cortical bone regions } \\
\qquad[\mathrm{MPa}] \\
\text { Allowed stress: } 70 \mathrm{MPa}\end{array}$} & \multicolumn{3}{|c|}{ Examined cases } \\
\hline & Standing on the healthy leg & Standing on both legs & Standing on the injured leg \\
\hline Direct plate technology & $\begin{array}{l}66.495 \text { - smaller part } \\
\text { of the sacrum }\end{array}$ & $\begin{array}{c}27.4976 \text { - smaller part } \\
\text { of the sacrum }\end{array}$ & $\begin{array}{c}38.1396 \text { - smaller part } \\
\text { of the sacrum }\end{array}$ \\
\hline H-plate + iliolumbar fusion & $\begin{array}{l}31.9222 \text { - bigger part } \\
\text { of the sacrum }\end{array}$ & $23.0433-5^{\text {th }}$ lumbar & $\begin{array}{l}35.5964 \text { - bigger part } \\
\text { of the sacrum }\end{array}$ \\
\hline $\begin{array}{l}\text { Pelvis screwing }+ \\
\text { iliolumbar fusion }\end{array}$ & $26.4753-4^{\text {th }}$ lumbar & $30.2540-4^{\text {th }}$ lumbar & $30.7423-4^{\text {th }}$ lumbar \\
\hline
\end{tabular}

Table 2. Maximal arising stresses in the cortical bone region 


\begin{tabular}{|c|c|c|c|}
\hline \multirow{2}{*}{$\begin{array}{l}\text { Arising maximal stress } \\
\text { in the cortical bone regions } \\
\text { [MPa] } \\
\text { Allowed stress: } 15 \mathrm{MPa}\end{array}$} & \multicolumn{3}{|c|}{ Examined cases } \\
\hline & Standing on the healthy leg & Standing on both legs & Standing on the injured leg \\
\hline Direct plate technology & $\begin{array}{c}14.7519 \text { - bigger part } \\
\text { of the sacrum }\end{array}$ & $\begin{array}{c}9.5197 \text { - bigger part } \\
\text { of the sacrum }\end{array}$ & $\begin{array}{c}9.2406 \text { - bigger part } \\
\text { of the sacrum }\end{array}$ \\
\hline H-plate + iliolumbar fusion & $0.799-5^{\text {th }}$ lumbar & $0.9106-5^{\text {th }}$ lumbar & $0.8791-5^{\text {th }}$ lumbar \\
\hline $\begin{array}{l}\text { Pelvis screwing }+ \\
\text { iliolumbar fusion }\end{array}$ & $\begin{array}{c}3.5758 \text { - bigger part } \\
\text { of the sacrum }\end{array}$ & $\begin{array}{c}3.5758 \text { - bigger part } \\
\text { of the sacrum }\end{array}$ & $\begin{array}{c}3.5139 \text { - bigger part } \\
\text { of the sacrum }\end{array}$ \\
\hline
\end{tabular}

Table 3. Maximal arising stresses in the spongiosa bone region

\begin{tabular}{|c|c|c|c|}
\hline \multirow{2}{*}{$\begin{array}{c}\text { Maximal elongation } \\
\text { of the ligaments [\%] } \\
\text { Allowed elongation: } 5 \%\end{array}$} & \multicolumn{3}{|c|}{ Examined cases } \\
\hline & Standing on the healthy leg & Standing on both legs & Standing on the injured leg \\
\hline Direct plate technology & $\begin{array}{c}0.0084 \text { - in the ligamentum } \\
\text { sacrospinal }\end{array}$ & $\begin{array}{c}0.0085 \text { - in the ligamentum } \\
\text { sacrospinal }\end{array}$ & $\begin{array}{c}0.0107 \text { - in the ligamentum } \\
\text { sacrospinal }\end{array}$ \\
\hline H-plate + iliolumbar fusion & $\begin{array}{c}0.0019 \text { - in the ligamentum } \\
\text { sacrospinal }\end{array}$ & $\begin{array}{c}0.0034 \text { - in the ligamentum } \\
\text { sacrospinal }\end{array}$ & $\begin{array}{c}0.0033 \text { - in the ligamentum } \\
\text { sacrospinal }\end{array}$ \\
\hline $\begin{array}{l}\text { Pelvis screwing }+ \\
\text { iliolumbar fusion }\end{array}$ & $\begin{array}{c}0.0024 \text { - in the ligamentum } \\
\text { sacrospinal }\end{array}$ & $\begin{array}{c}0.0029 \text { - in the ligamentum } \\
\text { sacrospinal }\end{array}$ & $\begin{array}{c}0.0038 \text { - in the ligamentum } \\
\text { sacrospinal }\end{array}$ \\
\hline
\end{tabular}

Table 4. Highest elongation values of the ligaments

\begin{tabular}{|c|c|c|c|}
\hline \multirow{2}{*}{$\begin{array}{c}\text { Maximal diplacement } \\
\text { between } \\
\text { the fracture ends }[\mathrm{mm}]\end{array}$} & Standing on the healthy leg & Standing on both legs & Standing on the injured leg \\
\cline { 2 - 4 } & 0.3123 & 0.1719 & 0.1965 \\
\hline Direct plate technology & 0.0718 & 0.0739 & 0.0801 \\
\hline H-plate + iliolumbar fusion & 0.1318 & 0.1410 & 0.1191 \\
\hline $\begin{array}{c}\text { Pelvis screwing + } \\
\text { iliolumbar fusion }\end{array}$ & & & \\
\hline
\end{tabular}

Table 5. Maximal displacement between the fracture ends

This is true to each examined case. In each case the elongation is considerable below the allowable threshold value. The highest value of elongation was measured during the direct plate technology, while during the H-plate and pelvis screwing technologies the amount of elongation is more than half of the previously mentioned. The highest elongations values are shown in the Table 4.
It is noticeable that during those methods using the iliolumbar fusion the displacement between the fracture ends is considerable lower than the direct plate technology. Furthermore the H-plate technology with iliolumbar fusion is even better than the pelvis screwing technology. The values of the displacement of the fracture ends are shown in the Table 5. 
It can be stated that the use of the direct plate technology with ventral position exposure can be avoided and justified. The H-plate technology using dorsal exposure is achieved with a considerably lower trauma. This technology results in smaller amount of stresses and provides higher stability.

\section{REFERENCES}

1. Abé H, Hayashi K, Sato M. Data Book on Mechanical Properties of Living Cells, Tissues, and Organs. Springer Verlag. Tokyo. 1996.

2.El-Asfoury MS, El-Hadek MA. Static and Dynamic Three-Dimensional Finite Element Analysis of Pelvic Bone. International Journal of Mathematical, Physical and Engineering Sciences 2009;3:1. p. 35-41.

3. Szentágothai J, Réthelyi M. Funkcionális anatómia I.. Bp.: Medicina Könyvkiadó Rt., 2002.

4. Burján T. A töréskezelés végeselemes modellezése medencegyưrû-sérülés esetén - Thesis. Bp.: BME GSZI 2003.
5. Dr. Varga E. A medencegyưrû sérülései. Available: http://www.vitalitas.hu/?ctype $=3$ \& todo $=$ bet\&id $=18 \&$ showbet $=2792$. Last accessed 2009 . 08.20 .

6. (2009). Finite element study of trochanteric gamma nail for trochanteric fracture. Available: http:// www.materialise.com/materialise/view/ en/393575-Finite +element + study + of + trochante ric + gamma + nail + for + trochanteric + fracture. html? cat $=2414683$. Last accessed 2009.08.29.

7. Cilingir AC, Ucar V, Kazan R. (2007). ThreeDimensional Anatomic Finite Element Modelling of Hemi-Arthroplasty of Human Hip Joint. Available: http://www.sbaoi.org/pdf/vol-21\%281\% 29/2116372.pdf. Last accessed 2009.09.16.

I would like to express my gratitude towards my two consultants Dr. Károly Váradi and Dr. Tamás Bodzay for belping and guiding my work. Furthermore I would like to say a special thanks to Tamás Burján, Cecília Bagdi and László Asbóth for letting me use their geometric model, which I developed further for my examinations and analysis. And last but not least I would like to thank Péter Mészáros for his help and support.

\section{János Simonovics}

Budapest University of Technology and Economics, Faculty of Mechanical Engineering Department of Machine and Product Design, Budapest H-1111 Budapest, Mûegyetem rkp. 3. 